\title{
The suitability of the International Certificate of Christian Education as an examination for university entrance
}

Jenna Scaramanga and Michael J. Reiss

UCL Institute of Education, UK

j.scaramanga.14@ucl.ac.uk

Word count: 7,947 words.

\section{Additional author information}

\section{Jenna Scaramanga}

orcid.org/0000-0001-5219-6672

Twitter: @jennascaramanga

Jenna Scaramanga attended an ACE school for four years. Her doctorate researched the experiences of students at Accelerated Christian Education schools in England. She has presented conference papers to the International Assocation of Critical Realism and by invitation to INFORM (Information Network on Religious Movements).

\section{Michael J. Reiss}

orcid.org/0000-0003-1207-4229

Michael J. Reiss is Professor of Science Education at UCL Institute of Education, Visiting Professor at the Universities of Kiel, Leeds and York and the Royal Veterinary College, a Fellow of the Academy of Social Sciences, President of the International Society for Science \& Religion and a Priest in the Church of England.

No potential conflict of interest was reported by the authors. 


\title{
The suitability of the International Certificate of Christian Education as an examination for university entrance
}

\author{
Increasing numbers of students are applying to university with the International \\ Certificate of Christian Education (ICCE), an alternative to mainstream \\ qualifications based on a biblically-based, individualised curriculum called \\ Accelerated Christian Education (ACE). No formal validity arguments exist for \\ the ICCE, but it claims to prepare students for university entrance. This article \\ assesses the validity of the ICCE by comparing the stated objectives in ACE \\ workbooks with the activities on its tests. It is argued that many of the learning \\ objectives are never tested at all. Those that are tested are frequently covered \\ only superficially. The tests rely extensively on rote memorisation which fails to \\ prove understanding of concepts, and ACE's definitions of academic disciplines \\ are often rather different from, and inferior to, the understandings of mainstream \\ academia. It is concluded that, while students from alternative educational \\ backgrounds should not be penalised, ICCE results cannot provide the robust \\ evidence of academic achievement that universities are entitled to expect.
}

Keywords: Accelerated Christian Education; curriculum; assessment; validity; Christian education

\section{Examinations for university entrance}

Throughout the world, an increasing number of mainly young people enter universities. Many universities are over-subscribed and use a number of ways of determining which applicants are deemed successful. Chief among these are examinations, either ones set by a university itself or, more usually, ones set by a nationally accredited body - e.g. 'A' (Advanced) levels in England and a number of other countries, set by a recognised Awarding Body. In this paper, the suitability of the International Certificate of Christian Education (ICCE), an award which claims to be suitable for determining the appropriateness of a candidate for admission to university, is examined. The ICCE is taken by students who have undergone Accelerated Christian Education. 


\section{Accelerated Christian Education}

Accelerated Christian Education (ACE) is 'a complete, self-instructional curriculum that integrates Bible truths and character values throughout all subjects and grade levels. Biblical principles and concepts are interwoven into all aspects of the programme ... and science is taught from the Biblical perspective of creation' (Christian Education Europe [CEE], 2017a). The curriculum consists mainly of PACEs (Packets of Accelerated Christian Education), workbooks typically around 40 pages in length, each of which takes a student approximately two weeks to complete (ACE, 2010). Students complete these workbooks at desks enclosed on three sides, known as offices (ACE, 2012, pp. 78-83).

ACE originated in Texas and now has its headquarters in Tennessee, but the standardised curriculum is distributed globally. It is used in around two dozen private schools in the UK (CEE, 2017b), and approximately 6,000 schools worldwide, as well as by 'thousands' of home schoolers (ACE, 2017). Although ACE has existed since 1970, with schools in the UK since 1979 (Dennett, 1988), it has been the subject of minimal research (Scaramanga, 2017). With increasing numbers of ACE students applying to universities and employers (Boulton, 2014), there is a need for more information about their qualifications and examination of their suitability.

Instead of receiving mainstream qualifications, students completing the ACE curriculum are awarded the International Certificate of Christian Education (ICCE). The ICCE has seven levels. This paper examines the General and Advanced levels, which NARIC (the designated United Kingdom national agency for the recognition and 
comparison of international qualifications and skills) has benchmarked as comparable to Cambridge International Exams 'O' and 'A' Level standard respectively (NARIC, 2012a). ACE is self-paced, so the age at which students graduate may vary, but the ICCE board expects the average student to complete the General certificate when aged 15-16 and the Advanced certificate when aged 17-18 (CEE, 2012, p. 17). Four ICCE subjects are examined: Biblical studies, English; science; and social studies (geography and history).

\section{About the ICCE}

Although ACE is an American curriculum, the ICCE was started by ACE's UK distributors, CEE, and is available in four regions: Europe, Africa, Australasia, and Southeast Asia. The ICCE claims to be 'a Christian alternative to secular qualifications' which 'provides graduating students with an internationally accepted qualification that enables them to gain entrance to universities and colleges around the world' (ICCE, 2017). The ICCE's chief moderator has claimed that more than 90 universities in the UK and 30 in other countries have accepted ICCE graduates (Boulton, 2014). In 2010, 236 ICCE certificates were awarded, of which 115 were at General level and 22 at Advanced (Lewis, 2013a). In 2011, 274 certificates were issued, 157 General and 38 Advanced (White, 2012). These were the only years for which data could be obtained. The sources do not specify whether these are worldwide or UK-only figures. 
Two of the ICCE's board members have clarified the reasons for ICCE's existence.

Writing in response to the introduction of GCSEs ${ }^{1}$, Stephen Dennett (now ICCE educational consultant) stated:

It is clear that GCSE poses a severe threat to the Judaeo-Christian ethic and to traditional education, in the best sense of the word ... Whatever happens, one truth remains: there can never be a truce between Zion and Egypt. A commitment to the kingdom of God is a declaration of war on Satan, the Prince of this world. Nowhere is that more true, at present, than in our national examination system. (Dennett, 1988, pp. 121-122)

More recently, addressing parents and other stakeholders, ICCE chair Brenda Lewis has said:

What's the alternative to doing ICCE Advanced certificate? You know what it is. Sending the children out at 16 to do A levels. An A level in biology? That's not going to be Creation-based is it? Nor is geology, nor the social sciences ...

[Before the ICCE's introduction] we wanted to do everything thoroughly, so we took our children off [the ACE curriculum] at 11 and taught them for GCSEs. And God bless them, they did extremely well at GCSE. But do you know what the real result was? We had students who were not much better or much different from state school students. (Lewis, 2013b)

\footnotetext{
${ }^{1}$ General Certificate of Secondary Education. GCSEs are taken in typically some six to ten subjects by the large majority of 15-16 year-olds in England each year.
} 
A promotional video gives some insight into the intended uses of the ICCE:

[ICCE] is a Christian alternative to conventional qualifications, such as GCSEs and A levels ... [The General certificate] is designed for average ability pupils and covers a standard and amount of work similar to 9 GCSEs grade $A^{*}-\mathrm{C}$... The advanced certificate is the board's university entry qualification. (DoverSchoolUK, 2013)

Clearly, the ICCE is intended to replace GCSEs and A Levels, national examinations taken by students in England and some other countries, typically at 16 and 18 years old respectively. Students from ACE schools apply to university using their ICCE certificates, yet there is little information available to university admissions tutors about the content or structure of the qualification. As a commercial, in-confidence document, UK NARIC's benchmarking study is not available to the public, and NARIC's international comparisons database (NARIC, 2012b) provides only limited information.

\section{Curriculum theory}

Just as the young-Earth creationism it teaches is a rejection of mainstream science, ACE represents a rejection of the presumptions of mainstream education. It rejects virtually all contemporary curriculum theory (Berliner, 1997), and has been vigorously criticized by mainstream academics (Beeke, 1992; Berliner, 1997; Fleming \& Hunt, 1987; Paterson, 2003; Speck \& Prideaux, 1993). Defending the company from one such critique, ACE's vice president responded:

We respect the right of Fleming and Hunt to disagree with us, but we ask that they evaluate our material from something other than the conventional 
viewpoint. Our material is not written with conventional viewpoints in mind. (Johnson, 1987, p. 520)

Similarly, ACE's Australian representative once argued 'ACE is not "on about" education in the sense that educators would understand, nor is it "on about" schooling in academic things. ACE is a Christian Character training program designed to turn out Christian leaders' (Murray, 1983, p. 71). Because the authors of the ACE curriculum reject mainstream educational theory, no attempt is made to evaluate the ICCE qualification within a framework based on current assessment theory. Research indicates that ACE has changed little since the 1980s (Kelley, 2005, p. 19; Scaramanga, 2017), so an evaluation repeating the assumptions of earlier researchers would be unlikely to yield new findings. Instead, ACE's assessments are evaluated on their own terms, investigating whether they achieve their objectives.

\section{Validity}

In order to judge an test's validity, there must be an explicit statement of the proposed interpretations and uses of test scores (American Educational Research Association, American Psychological Association, \& National Council on Measurement in Education, 1999, p. 9). It is not so much tests themselves that are valid or not, but the inferences drawn from them (Markus, 1998, p. 80). Without knowing the uses for which a test is designed, it is impossible to validate it. Therefore, test publishers need to 'provide enough of the right kind of information for other stakeholders to evaluate their products and to use them appropriately' (Newton, 2012, p. 18). 
In the case of the ICCE, it appears that no such argument has been made. There is no reference to validity on the ICCE website, nor in the International Certificate of Christian Education Procedures Manual (CEE, 2012). No clear statement of the proposed interpretations and uses of ICCE test scores could be found. Equally, no validity argument for the ACE curriculum on which the ICCE is largely based could be found. Elkins (1992) argues that ACE does not consider itself accountable to anyone except its users, which may explain why the curriculum has not undergone a process of external validation.

Because there is no available validity argument for either ACE or the ICCE, and no statement about the intended inferences to be drawn from their test scores, it is not really possible to evaluate the validity of the ICCE curriculum. However, since students are applying to university on the basis of these qualifications, it would still be useful to understand what the tests measure. This has been attempted by comparing PACEs' stated learning objectives with the activities in PACE tests. As a result, this paper examines the ICCE on its own terms; in that sense, this paper risks being less critical of the ICCE than some would judge it should be. At the end of each PACE, students take a summative test. It is the scores from these tests which dominate ICCE assessment. The grades on a student's ICCE certificate are reached by calculating the student's mean PACE test score for each subject.

\section{PACE learning objectives}

Historically, validity was defined as 'the degree to which a test or examination measures what it purports to measure' (Ruch, 1924, cited in Newton, 2012, p. 3). While most validity theorists no longer consider this a sufficient definition, it remains an 
important component of validity. If tests do not measure what they purport, inferences based on test scores will inevitably be faulty. It is therefore worth investigating whether the PACE tests succeed in measuring their stated learning objectives. This could not be done in every case, because not all PACEs used in the ICCE contain measurable objectives. PACEs numbered 1097 and above, however, contain learning objectives of the form 'When you have successfully completed this PACE, you should be able to ...' followed by a list of (mostly) specific outcomes. The PACE tests can then be evaluated by asking whether they measure the knowledge and skills listed in the objectives.

The subjects Biblical studies, English, science and social studies (geography and history) were selected because they are compulsory for all students at both General and Advanced levels. The only other compulsory subject, mathematics, was not studied because of the very different type of questions it contains. At General level, all the available PACEs in those subjects were examined. By now it was clear that one PACE in a particular subject is very much like another. At Advanced level three PACEs in each of the relevant subjects were therefore purchased by choosing ones either at random or because we knew they were of particular interest (e.g. English PACE 1144 which has the only compulsory speaking assignment in the English curriculum). The analysis of learning objectives in PACEs (Tables 1-4) included every available PACE in each subject. Learning objectives for those PACEs not purchased were viewed online at Christianbook.com.

Before discussing how well the PACE tests measure the stated objectives, it is important to understand what these objectives are. A useful way to classify the types of objectives is by the action verbs used (e.g. 'Memorize the eight parts of speech'; 'Name 
the parts of a typical neuron'). All of the verbs in the objectives for the examined PACEs were listed and their frequencies counted (Tables 1 and 2).

[Table 1 near here]

[Table 2 near here]

Having examined these objectives, it needs to be determined what kinds of activity would indicate successful completion: what must students $d o$ to demonstrate they have fulfilled the objective in question?

The Taxonomy of Educational Objectives (Bloom, 1956) provides an established and comprehensive framework for identifying instructional objectives (Gronlund \& Brookhart, 2008). This appears to be one educational theory ACE does accept (e.g. ACE, 2014). As is well known, Bloom's taxonomy divides learning into a hierarchy of six dimensions: knowledge (remembering), comprehension (understanding), application, analysis, synthesis (combining previous learning or producing something new), and evaluation. It is possible to categorize learning objectives using the taxonomy by classifying action verbs into each level (Almerico \& Baker, 2004). Verbs such as 'learn', 'list', and 'memorize' relate to the knowledge level because they require only recall, while 'explain' or 'paraphrase' are at the comprehension level because they require students to demonstrate understanding. All the verbs in the PACE objectives 
were classified in this way. Numerous lists exist for this purpose; in this case, examples from Cornell University ${ }^{2}$ and the University of Greenwich ${ }^{3}$ were employed.

A few of the verbs are not easily classified. Depending on context, 'identify' can indicate knowledge or comprehension. In most instances, PACEs use 'identify' to refer to knowledge rather than comprehension activities. Some PACE objectives defy categorisation, either because of vagueness ('to have a general idea of', Basic New Testament Church History 130) or by referring to spiritual rather than academic aims ('to apply God's promises to your daily life', Science [Chemistry] 1127). These were omitted from the analysis. Tables 3 and 4 show the results of this classification.

[Table 3 near here]

[Table 4 near here]

ACE has been criticized for its neglect of higher-order thinking skills (Berliner, 1997; Speck \& Prideaux, 1993). Looking at Tables 3 and 4, it becomes clear that the PACEs, in the main, do not aim to develop higher-order thinking skills; overall $86 \%$ of learning objectives are at the knowledge or comprehension level. This is one example of the 'philosophical differences' between ACE and many mainstream educators (Johnson, 1987, p. 520).

\footnotetext{
${ }^{2}$ https://www.cte.cornell.edu/documents/Assessment\%20\%20Blooms\%20Taxonomy\%20Action\%20Verbs.pdf, retrieved 14 March 2017.

${ }^{3}$ http://cms1.gre.ac.uk/mmt/news/Blooms.html, retrieved 13 May 2016.
} 


\section{Measurement of objectives}

Having established what the PACE objectives are, the question of whether the PACE tests successfully measure them arises. To investigate whether PACEs' assessments are aligned with their objectives, one quarter (i.e. three) of the available PACEs in each subject were examined. The PACEs were chosen using a random number generator. The results of this investigation are found in Table 5.

[Table 5 near here]

'Measured' in Table 5 means that the PACE test contains one or more items that, if completed successfully, would demonstrate satisfactory mastery of the objective. 'Inadequately measured' means there is at least one test item relevant to the objective, but correctly answering the question would be insufficient to demonstrate full attainment of that objective. 'Not measured' means that there were no items on the test relevant to the given objective.

Inadequately measured objectives are most often those requiring comprehension or a higher-order thinking skill, but which are assessed using recall only. BNTCH 129 has the objective 'to discuss the Anabaptist movement'. The test has three relevant items, but none of them allows for discussion: the student must match 'Anabaptist' with the term 're-baptizer', and answer two true/false questions on the subject. In English 1121, objectives include 'To learn how to evaluate literature' and 'To read and evaluate American literature from the Colonial Period', but the test only requires students to complete (from memory) rules for evaluating literature (underlined text indicates the blank to be completed): 
(1) Exercise discipline and control over what you allow to come into your mind.

(2) Distinguish between the foolishness of this world and the wisdom of God.

(3) Reject that which glorifies sin.

(4) Read what is profitable for spiritual growth.

In some cases, objectives are measured by the test, but only thinly. In Science 1099, objectives include 'To describe the class of fish that includes lampreys and hagfish' (Agnatha), 'To describe fish such as sharks, rays, and skates' (Chondrichthyes) and 'To describe bony fish' (Osteichthyes). Test item 12 (worth 2.5\%) duly asks students to 'Describe the three classes of fish'. However, the answer required is 'Agnatha do not have jaws ... Chondrichthyes have cartilage skeletons ... Osteichthyes have bony skeletons'. This is a thin kind of 'description', and it is doubtful whether these are sufficient definitions. By the PACE text's own account, members of class Agnatha also have cartilage skeletons, so the descriptions fail to distinguish between the classes. Nevertheless, these objectives were classified as 'measured' for the purposes of Table 5, since students' knowledge of the PACE's descriptions is tested.

The large number of PACE objectives that are not thoroughly measured by the tests can be explained by the number of recall activities in the PACE tests. Overall, $50 \%$ of PACE objectives are at the knowledge level (Table 3), and therefore can adequately be tested by recall activities. The rest of the PACE objectives are at the comprehension level or above, so they require other kinds of test activity in order to measure them. In the PACEs and PACE tests, however, non-recall items are rare. Tables 6 and 7 show 
that in most cases, the tests consist exclusively of recall activities, mainly fill-in-theblank and multiple choice.

[Table 6 near here]

[Table 7 near here]

The non-recall activities in English tests at General level are mostly technical grammar exercises. The majority involve sentence diagrams, pictorial representations of sentence structure based on the system devised by Reed and Kellogg (1880). Other activities involve the application of grammar rules, such as adding missing punctuation to given sentences or underlining words that ought to be capitalized. In English 1095, students are asked to add the missing addresses, salutation, and closing to a pre-written business letter. Earlier in the PACE, students are given the opportunity to write their own letters, but these do not form part of the test score. At General level, only two PACE tests offer students the opportunity for extended writing: English 1094 and English 1096. In the former, $40 \%$ of available marks are for preparing and writing 'an interesting paragraph'. In the latter, $30 \%$ of marks go to writing a three-paragraph biographical report on Florence Nightingale, which students must complete from a supplied outline. At Advanced level, all examined English tests require only recall or comprehension except English 1144, for which $30 \%$ of marks were for giving a six- to ten-minute speech. This is the only speaking activity in any of the examined PACEs. In the examined physics and chemistry tests, non-recall activities were all for mathematical calculations.

\section{Objectives as measures of PACE content}


It might be argued that the learning objectives apply to the entire PACE workbook, so it is unfair to look at the tests in isolation. While this is true, there are several reasons to doubt that completion of a PACE entails the satisfaction of its stated objectives. The first is that, in some cases, the PACEs contain objectives which are satisfied by none of the PACE activities. Seven of the examined English PACEs included an evaluation objective. Of these, four contain no evaluation activities. The opportunities that do arise are quite restrictive. English 1121 (p. 16), intended for students in their third year of high school, asks: 'Do you think "Housewifery" is a good title for the poem? Why, or why not?' There is one line on which to write the answer.

\section{Insistence on verbatim recall}

An easy way to distinguish understanding from parrot-fashion repetition is to ask the student to explain something in her own words. This is discouraged by ACE, however. If a student uses a synonym rather than the exact word given in the score key, she loses half a mark (CEE, 2010, p. 41). In the case of these examples:

Love is not an emotion, but a conscious . (Science [Biology] 1107, test item \#30)

After nine generations of history, God decided to destroy mankind and Earth because of man's . (Social Studies [Geography] 1097, test item \#8)

The correct answers are 'choice' and 'unrepentant wickedness' respectively. The student would be penalized for writing 'decision' and 'sinfulness', even though these 
answers demonstrate adequate understanding. This incentivizes unthinking memorization.

Since PACE activities typically require only verbatim repetition, completing the PACE without understanding will not hinder the student's progress. Some students might conclude that learning consists only of recall and remain unaware of gaps in their own understanding. ACE suggests supervisor 'quizzing' of students to avoid this (ACE, 2010, p. 108), but since no record is kept of these informal quizzes, they cannot be used as evidence of the validity of the ICCE. With the only requirement to teach in an ACE school being a week's training (ACE, 2016), the quality of teaching is likely to be variable.

\section{Retention}

From the style and content of the PACEs, it can be inferred that ACE believes the purpose of academic education is the mastery of a body of facts. If this is the case, retention of those facts becomes a critical issue. The PACE assessments do not give any indication of the students' long-term recall of information. Each PACE test asks questions only about material from the current PACE; a PACE typically takes 2-3 weeks to complete (ACE, 2010, p. 85). Students take the tests whenever they are ready (ACE, 2010, p. 109), usually the day after completing the PACE. This system encourages cramming (or 'massed presentation'), which is likely to reduce long-term retention (Bahrick \& Hall, 2005; Dempster, 1988).

\section{Critical thinking}


None of the examined tests included the opportunity for analysing or evaluating. Apart from the mentioned exceptions in English 1094, 1096, and 1144, none involved any creating. The PACE tests provide evidence for remembering and sometimes understanding. If readiness for university involves the development of skills of analysis, creativity, and evaluation, the ICCE seems unlikely to constitute suitable preparation.

Still, it could be argued that university preparation ought to focus on learning and understanding a body of knowledge, and that the skills of application, analysis, and evaluation can be developed later. The PACE tests might plausibly provide evidence that this kind of learning has taken place. The validity of this argument is therefore considered.

\section{Validity threats}

A validity threat is any piece of negative evidence that may undermine inferences drawn from an assessment (Crooks, Kane, \& Cohen, 1996). Crooks, Kane, and Cohen's framework breaks the process of validation into a chain of eight linked stages: administration, scoring, aggregation, generalization, extrapolation, evaluation, decision and impact. There are particular threats to the validity of conclusions based on PACE test scores at the administration, scoring, aggregation, generalisation, and extrapolation stages.

\section{Administration}

Tests are marked from answer keys by supervisors in schools (or by parents in the case of home-schooled students). A sample of these tests is moderated externally. A potential threat to test administration in ACE is that only one test exists for each PACE. If a 
student fails the test, they repeat the PACE before taking the same test again. If she passes on the second or third attempt, the passing score is recorded with no penalty; on fourth or subsequent attempts, the mark is capped at $80 \%$ (CEE, 2012, p. 79). This means that a student who failed the first time will be able to prepare for the test knowing exactly what questions will be asked, but the mark will not reflect this.

\section{Scoring}

The usefulness of scores is threatened if it is possible for students to answer correctly without employing the attribute the test is intended to measure. It must be asked, therefore, whether a passing PACE test score proves that the student has understood the content. There are reasons to doubt this beyond those already discussed.

Multiple choice questions on PACE tests sometimes include implausible distractors yet it is universally acknowledged that distractors must be plausible for multiple choice questions to be effective (Haladyna, Downing, \& Rodriguez, 2002, p. 314). Examined PACE tests included items such as:

The leader of the Katanga Province was

a. Patrick Henry b. Mohammed Ali c. Moise Tshombe (Social Studies [World History] 107, test item \#6)

When an actor speaks to himself alone on the stage to let the audience know what he is thinking and feeling, he is (giving a soliloquy, faking insanity, a poor actor, about to be killed).

(English 1135, test item \#8) 
At times, distractors seem to be chosen in order to reinforce the authors' ideology rather than to measure learning:

The title of Charles Darwin's famous book was

\author{
a. Top Banana in the Jungle \\ b. The Origin of Species \\ c. Nobody is Going to Make a Monkey Out of Me \\ (Social Studies [World History] 106, test item \#21)
}

(Gregor Mendel, Adolf Hitler, Charles Darwin, Charles Mendel) formulated the theory of evolution. (Science [Biology] 1107, test item \#1)

PACE tests also make frequently use of association activities, where students match words with their definitions from two lists, or events with their dates. Other activities include fill-in-the-blank items where answers are chosen from a list. These have the common flaw that answers are not independent of each other (Haladyna et al., 2002, p. 314). One incorrect answer can jeopardize other items; in other cases, students can find answers by a process of elimination. This makes the assessment in part a measure of test-wiseness.

\title{
Aggregation
}

When all tasks have been scored, they can be combined together to produce totals. If scores from excessively diverse tasks are included in one total, the correlations between 
tasks may be low and the resultant score of limited meaning. Alternatively, if diverse tasks are given inappropriate weights, the total may be misleading.

An ACE selling point is that no distinction is made between religious knowledge and subject-specific knowledge; religious lessons are integrated into every academic subject. Most tests also contain at least some questions of a religious nature. This means that a student's knowledge of the Bible, or of fundamentalist doctrine, affects their test scores in such unrelated disciplines as science and geography. Scripture memorization is part of assessment in all PACEs for the first year of ICCE, and in every English PACE. In the British history PACEs reviewed, Scripture memorization formed a mean of $2.0 \%$ of the total marks; in Earth science, $2.5 \%$; in English, 3.7\%. These are small amounts; however, grade boundaries are narrow in the ICCE (see Table 8).

[Table 8 near here]

English PACEs numbered 1097 and above contain 'Wisdom inserts' - pull-out comics designed to impart godly character. From PACE 1100 onwards, questions about these inserts form part of the PACE tests. In the examined English tests that included Wisdom questions, they formed a mean $7.6 \%$ of marks. On these PACEs, scripture memorisation and Wisdom questions made up $11.4 \%$ of the total score, while each grade boundary is just 4\% wide. In the reviewed English PACEs numbered 1121-1144, there were further questions of a devotional nature, not labelled as 'Wisdom'. In English 1130, 30\% of marks were for questions related to 'The Bible or Evolution', a speech by anti-evolution campaigner William J. Bryan. Example Wisdom questions include: 
Of the following, all but are necessary elements of wisdom.

a. discerning what is right and wrong from God's viewpoint

b. debating in our own minds to determine what is right and wrong

c. doing what Jesus would do if He were in our circumstances

d. determining to obey God regardless of the consequences

(English 1100, test item \#34; correct answer is 'b')

True or false: Responsible Bible-believing citizens should refuse government handouts. (English 1108, test item \#24; correct answer is 'True')

If an ICCE student's Record of Achievement shows a ' $C$ ' grade for English, then, it is possible that the student in fact gained full marks on the English activities, and only lost marks on religious questions. The ACE aggregation offers no way of knowing.

In addition to Scripture memorisation, tests frequently contain questions of religious belief that appear for devotional reasons. Although these are matters of faith, each question has only one 'correct' answer. Examples include:

True happiness can only be found through faith in Jesus Christ.

(Science [Biology] 1105)

True or false: Our peace - as Christians - is in Jesus Christ.

(Social Studies [World History] 107) 
Because God desires fellowship with all men, it is our responsibility to take His message to those who have never heard.

(Social Studies [Geography] 1097)

These questions make up only a small minority (2-3\%) of marks in most subjects, but this is enough potentially to change a student's overall grade (see Table 8). Those evaluating ICCE grades should bear in mind that the test scores combine religious learning with the academic disciplines.

\section{Generalization}

Generalization is the assumption that scores are indicative of a student's predictive performance in the assessed domain. It is theorized that test items represent a random sample of questions which might have been asked; scores are taken as an indication of the student's likely performance in this wider pool of questions. In the case of PACE tests, however, students have an excellent idea of which parts of the PACE will be on the test.

Each PACE contains three review sections called 'checkups', and a final review called a 'self test'. Checkups are typically two pages long. Questions for both the self test and test are drawn exclusively from the checkups. This is not stated explicitly, but before taking the test, students are advised in each PACE to revise the checkups. This means that, although PACEs are typically 40-50 pages, students need revise only six pages to gain full marks. Since this is the case in all PACEs, it is probable that at least some students will pay less attention to the other 'unimportant' material. 
In some subjects, they need not revise even this much. In the World History PACEs, $94.5 \%$ of test marks go to questions repeated from the self test (usually three pages). In British History, it is $100 \%$. Even if their supervisors do not point this out, presumably at least some students will notice this pattern. Students usually take the self test the day before the test (CEE, 2010, p. 39) and mark it themselves from an answer key. They have, in effect, a completed test from which to revise, making it doubtful whether students' test scores would generalize to performance in other contexts.

\section{Extrapolation}

The assessed domain is a subset of the target domain, and test scores are used to extrapolate from the former to the latter. If the test questions are not representative of the target domain, such extrapolation may be unwarranted; this may be exacerbated if performance on included tasks is not well correlated with performance on the excluded tasks (Crooks et al 1996, 275). The ICCE does not clearly specify the target domain for each of its subjects, but it might reasonably be assumed that such terms as 'English', 'history', and 'geography' refer to the understandings of experts in these subjects in mainstream academia. Many ACE subjects, however, define their areas more narrowly than is usual, and in some cases reject important findings and methods from their disciplines. Those making decisions based on ICCE test scores should be aware of differences between ACE's version of academic disciplines and those in mainstream schools.

The most obvious point of departure is science; ACE rejects all aspects of science which do not conform to its literal interpretation of the Bible. This also affects the study of ancient history, since ACE believes the Earth to be approximately 6,000 years old, 
and that a global flood destroyed civilization 4,500 years ago. Even in areas unrelated to creationism, many ACE subject areas are notably unlike the same subjects as taught in mainstream education. Although there is a limited discussion of geographical concepts such as plate tectonics, ACE's geography course mostly consists of memorizing the names and locations of countries, with an emphasis on the work of missionaries on each continent. The study of human geography, as understood in mainstream schooling, is skeletal or absent. ACE's English programme focuses much more on traditional grammar, and much less on literature and creative writing, than do most English courses.

\section{Impact}

The final step in the validity chain considers the impact of the assessment regime on students. 'The effort involved in the assessment process can only be justified if the assessment leads to worthwhile benefits for students or other stakeholders' (Crooks et al., 1996, 279). It seems evident that assessment which rewards rote learning while ignoring or penalizing other kinds of understanding presents the student with a distorted view of what learning is. Most importantly, the ICCE's weaknesses seem likely particularly to impact students of lower ability. The ACE system does not provide students with coherent frameworks to make sense of the facts they memorize, nor encourage them to make connections between disparate areas of learning. It is plausible that some students might succeed in understanding the material and could excel despite the system's weaknesses. Others, however, are at risk of mistaking rote memorization for genuine learning, of struggling with long-term retention, and of lacking a coherent framework within which to make sense of the facts they learn. These students could be hindered from reaching their academic and personal potential. 


\section{Coursework}

NARIC (2012a, 2012c) stresses that the ICCE qualification involves more than just the ACE materials, and its comparability statement is for the entire ICCE, and not PACE tests in isolation. The analysis presented here has not considered what impact the compulsory coursework elements of the ICCE might have on its validity. It should though be noted that these elements are weighted at just $2 \%$ of total assessment at General level (CEE, 2012, p. 54). At Advanced level, one-third of units are coursework, but, according to CEE (2012, p. 54), at Intermediate and Advanced levels, coursework, though graded pass/merit/distinction, has no formal weighting and no impact on the student's subject grades or overall grade.

No example essays were available for review, but the majority of assignment titles appeared appropriate. They included study of classic literature and practical science, which are notably absent from the ACE curriculum. Nevertheless, there may still be cause for concern with some aspects of even this. For example, past essay titles have included 'In what ways, if any, was Alexander the Great a type of the Antichrist?'. In both English and science, one essay option involves arguing against the theory of evolution and defending creationism.

In general, there is insufficient evidence available to comment on the validity of ICCE coursework. Potentially, the essays could go some way towards making up for the lack of extended writing opportunities in the PACEs. It is difficult to see, however, how these coursework items could compensate for all the weaknesses identified in ICCE assessments. 


\section{Discussion}

The ICCE maintains that it prepares students for university entrance. In the absence of a validity argument for the ICCE, it is impossible to assess its validity closely. On the available evidence, however, it is difficult to see how valid inferences can be drawn with confidence from ICCE test scores. It might be argued that a lot of assessment goes on all over the world that is not in line with high quality education and psychological association standards. In response, two rejoinders can be made. First, this may indeed be the case and there are no doubt other qualifications that have shortcomings; however, the focus here is on the ICCE. Secondly, without claiming to be in a position to make any sort of systematic judgement about the quality of the ICCE relative to other qualifications, it does seem that by comparison with the most widely available alternatives in England, the ICCE falls well short.

A number of specific threats seem to undermine any attempt to draw meaningful conclusions from ICCE test scores:

1) It is possible for students to answer most PACE test questions without understanding.

2) The tests frequently fail to measure their stated objectives.

3) Students are able to re-take exactly the same test for a second and third time without penalty.

4) The assessment regime provides no evidence of students' long-term retention of information. 
5) The subject areas, as defined by ACE, are in many cases rather different from how these disciplines are understood by mainstream academia.

This is not to say that it is impossible for ICCE students to succeed once they have left behind their ACE curriculum. Indeed, anecdotal evidence suggests that some ICCE graduates have excelled at university (Johns \& Hallett, 2014). Students in ACE schools do not receive many of the opportunities afforded students in mainstream schools; Speck and Prideaux (1993, p. 293) argue that they are "in a state of conceptual and cognitive disadvantage". It would be unfortunate if they were further disadvantaged by universities and colleges rejecting the ICCE as a matter of policy. It is not helpful, however, to accept students onto FE or HE courses for which they are unprepared, as ICCE students may be.

It is therefore appropriate for universities at the present time to recognise two things when faced with applications from students who have ICCE qualifications. First, students may perform well on the ICCE yet be poorly prepared for university entrance. Universities should therefore be sceptical about the value of ICCE as a university qualification. Secondly, and somewhat in contradistinction, any student applying to higher education with an ICCE qualification is likely to have experienced a restricted school education. It is therefore possible that such students may eventually perform better in a higher education institution, as a result of the teaching they receive, than might initially be thought. Such students will benefit from the opportunity to thrive in a richer educational environment. 
However, the stronger conclusion is that substantial improvements are urgently needed to the ways in which ICCE qualifications are determined, if such qualifications are to continue to be permitted. Both NARIC, the designated United Kingdom national agency for the recognition and comparison of international qualifications and skills, and ACE schools themselves need to ensure that students are prepared for high quality, nationally recognised qualifications. It is not in students' interests for them to spend years of their lives studying for poor quality qualifications. At present NARIC's benchmarking of ICCE is not available to the public. There would seem to be an argument for greater transparency in this respect.

Finally, it should be noted that many advocates of faith-based (including Christian) education would also be critical of the ICCE and, more generally, ACE's approach to education. It is not intended that this paper be read as an attack on religion or on the possibility of high quality religious education (cf. Hand, 2012). Furthermore, it has been argued that parents are entitled to bring their children up in a particular religion (cf. Brighouse \& Swift, 2016). The argument of this paper is simply that if readiness for university involves the development of skills of analysis, creativity, and evaluation, or even simply learning and understanding a body of knowledge, the ICCE does not provide adequate preparation.

\section{Notes}

The PACE examined for this review were:

Basic Life of Christ 133, 143, 144; Basic New Testament Church History 121-132;

Basic New Testament Survey 97-108; English 1085-1108, 1120, 1127, 1129, 1130, 1134, 1135, 1142-1144; Geography 1097, 1099, 1101, 1104, 1106, 1108; History of 
Civilization II 20; Science 1085-1108, 1121, 1137, 1140, 1141; Social Studies 97-108, UK1085-UK1096, 1097, 1099, 1101, 1104, 1106, 1108, 1139.

In all cases the author and publisher is Accelerated Christian Education. Place of publication is not given.

\section{References}

ACE. (2010). Procedures Manual I: Learning Center Essentials. Nashville, TN: ACE.

ACE. (2012). Administration Manual. Nashville, TN: ACE.

ACE. (2014, September). Developing Critical Thinking Skills (Part 1). Accelerator, 7.

ACE. (2016). Training. Retrieved 20 March 2017, from

http://www.aceministries.com/training/?content=main

ACE. (2017). A.C.E. Distinctives. Retrieved 20 March 2017, from

https://www.aceministries.com/curriculum/?content=main\&distinctive=individu alized\#Distinctive_2

Almerico, G. M., \& Baker, R. K. (2004). Bloom's Taxonomy Illustrative Verbs:

Developing a Comprehensive List for Educator Use. Florida Association of Teacher Educators Journal, 1(4), 1-10.

American Educational Research Association, American Psychological Association, \& National Council on Measurement in Education. (1999). Standards for Educational and Psychological Testing. Washington, DC: AERA.

Bahrick, H. P., \& Hall, L. K. (2005). The importance of retrieval failures to long-term retention: A metacognitive explanation of the spacing effect. Journal of Memory and Language, 52(4), 566-577.

Beeke, J. W. (1992). An Evaluation of the Accelerated Christian Education (A.C.E.)

Program for the Purpose of Group I Independent School Classification: 
Summary Report. Ministry of Education, Independent Schools Branch, British Columbia.

Berliner, D. C. (1997). Educational psychology meets the Christian Right: Differing views of children, schooling, teaching and learning. Teachers College Record, $98(3), 381-416$.

Bloom, B. S. (Ed.). (1956). Taxonomy of Educational Objectives: The classification of educational goals. Handbook 1: Cognitive domain. New York: David McKay.

Boulton, L. (2014, August 29). Religious education is a rounded education. Times Education Supplement. Retrieved from http://www.tes.co.uk/article.aspx?storycode $=6440952$

Brighouse, H., \& Swift, A. (2016). Family Values: The Ethics of Parent-Child Relationships. Princeton: Princeton University Press.

CEE. (2010). TEACH: Home Education Handbook. Unknown: CEE.

CEE. (2012). International Certificate of Christian Education Procedures Manual. Swindon: CEE.

Christian Education Europe. (2017a). Bible-Based Curriculum. Retrieved 20 March 2017, from http://christian.education/curriculum/

Christian Education Europe. (2017b). Schools. Retrieved 20 March 2017, from http://christian.education/schools/

Crooks, T. J., Kane, M. T., \& Cohen, A. S. (1996). Threats to the Valid Use of Assessments. Assessment in Education: Principles, Policy \& Practice, 3(3), 265-286.

Dempster, F. N. (1988). The spacing effect: A case study in the failure to apply the results of psychological research. American Psychologist, 43(8), 627-634. https://doi.org/10.1037/0003-066X.43.8.627 
Dennett, S. (1988). A Case for Christian Education. Bradford: Harvestime.

DoverSchoolUK. (2013). Dover School for All Nations: Educating for Eternity. Retrieved 20 March 2017, from http://youtu.be/OnvqJC-YwTE

Elkins, H. L. (1992). A description of Apostolic schools in Indiana (Unpublished doctoral dissertation). Indiana University.

Fleming, D. B., \& Hunt, T. C. (1987). The world as seen by students in Accelerated Christian Education. Phi Delta Kappan, 68(7), 518-523.

Gronlund, N. D., \& Brookhart, S. M. (2008). Gronlund's Writing Instructional Objectives (8th edition). Upper Saddle River, NJ: Pearson.

Haladyna, T. M., Downing, S. M., \& Rodriguez, M. C. (2002). A review of miltiplechoice item-writing guidelines for classroom assessment. Applied Measurement in Education, 15(3), 309-333.

Hand, M. (2012). What's in a worldview? On Trevor Cooling's Doing God in education. Oxford Review of Education, 38, 527-537.

ICCE. (2017). Introducing ICCE. Retrieved 20 March 2017, from http://icce.education/about/international-certificate-of-christian-education/

Johns, T., \& Hallett, E. (2014, June 12). Life in a Christian 'fundamentalist' school. BBC. Retrieved 20 March 2017, from http://www.bbc.co.uk/news/uk-england27681560

Johnson, R. E. (1987). ACE Responds. Phi Delta Kappan, 68(7), 520-521.

Kelley, L. (2005). An Analysis of Accelerated Christian Education and College Preparedness Based on ACT Scores (Ed.S.). Marshall University. Retrieved from http://mds.marshall.edu/cgi/viewcontent.cgi?article=1093\&context=etd

Lewis, B. (2013a, April 8). Dover School for All Nations: Value of the ICCE - Part 1. Retrieved 20 March 2017, from https://youtu.be/oPEj7Z-toG0 
Lewis, B. (2013b, April 8). Dover School for All Nations: Value of the ICCE - Part 2. Retrieved 20 March 2017, from https://youtu.be/bKUPXBljp1A

Markus, K. A. (1998). Validity, facts, and values sans closure: Reply to Messick, Reckase, Moss, and Zimmerman. Social Indicators Research, 45(1-3), 73-82.

Murray, M. J. (1983). Alternative Christian schools : a critical examination of the theory and practice of accelerated Christian education and other similar school programs (Unpublished dissertation for course 1SO 40). Brisbane College of Advanced Education, Kelvin Grove, Australia.

NARIC. (2012a). Benchmarking ICCE Qualifications. Retrieved 20 March 2017, from http://www.ecctis.co.uk/naric/news\%20story.aspx?NewsID=106

NARIC. (2012b). International Comparisons: International Certificate of Christian Education (ICCE). Retrieved 7 November 2013, from https://www.naric.org.uk/Product/International\%20Comparisons/appendices/chr istian\%20education.aspx

NARIC. (2012c). UK NARIC benchmarking statement. Retrieved 20 March 2017, from http://www.ecctis.co.uk/NARIC/news\%20story.aspx?newsid=167

Newton, P. E. (2012). Clarifying the consensus definition of validity. Measurement: Interdisciplinary Research and Perspectives, 10(1-2), 1-29.

Paterson, F. R. A. (2003). Democracy and Intolerance: Christian school curricula, school choice, and public policy. Bloomington, IN: Phi Delta Kappan.

Reed, A., \& Kellogg, B. (1880). Higher Lessons in English. New York: Clark \& Maynard. Retrieved 20 March 2017, from https://archive.org/details/higherlessonsin09kellgoog

Scaramanga, J. (2017). Systems of Indoctrination: Accelerated Christian Education in England (Unpublished doctoral thesis). University College London, London. 
Speck, C., \& Prideaux, D. (1993). Fundamentalist Education and Creation Science. Australian Journal of Education, 37(3), 279-295.

https://doi.org/10.1177/000494419303700305

White, S. (2012). ICCE Information Sheet No. 26. Unknown: ICCE. 
Table 1. ICCE General: five most common verbs in PACE objectives.

\begin{tabular}{|l|l|}
\hline Verb & Appearances \\
\hline Identify & 61 \\
Describe & 41 \\
Learn & 34 \\
Understand & 29 \\
Name & 28 \\
\hline
\end{tabular}

Table 2. ICCE Advanced: five most common verbs in PACE objectives.

\begin{tabular}{|l|l|}
\hline Verb & Appearances \\
\hline Identify & 78 \\
Explain & 72 \\
Describe & 47 \\
Understand & 47 \\
State & 43 \\
\hline
\end{tabular}

Table 3. Learning Objectives in ACE PACEs by subject

\begin{tabular}{|llllll|}
\hline & English & Social Studies & Science & Bible & All \\
\hline Knowledge & $154(64 \%)$ & $104(47 \%)$ & $147(38 \%)$ & $114(57 \%)$ & $519(50 \%)$ \\
Comprehension & $4(2 \%)$ & $105(47 \%)$ & $192(50 \%)$ & $71(36 \%)$ & $372(36 \%)$ \\
Application & $35(15 \%)$ & 0 & $37(10 \%)$ & $6(3 \%)$ & $78(7 \%)$ \\
Analysis & $4(2 \%)$ & $14(6 \%)$ & $7(2 \%)$ & $8(4 \%)$ & $33(3 \%)$ \\
Synthesis & $20(8 \%)$ & 0 & 0 & 0 & $20(2 \%)$ \\
Evaluation & $22(9 \%)$ & 0 & 0 & 0 & $22(2 \%)$ \\
\hline
\end{tabular}

Table 4. Learning objectives in ACE PACEs by ICCE certificate level

\begin{tabular}{|lll|}
\hline & General & Advanced \\
\hline Knowledge & $254(62 \%)$ & $265(42 \%)$ \\
Comprehension & $119(29 \%)$ & $253(40 \%)$ \\
Application & $28(7 \%)$ & $50(8 \%)$ \\
Analysis & $3(1 \%)$ & $30(5 \%)$ \\
Synthesis & $9(2 \%)$ & $11(2 \%)$ \\
Evaluation & $0(0 \%)$ & $22(3 \%)$ \\
\hline
\end{tabular}


Table 5. Learning objectives in PACEs by subject

\begin{tabular}{|lllll|}
\hline Subject & $\begin{array}{l}\text { Number of } \\
\text { objectives }\end{array}$ & Measured & $\begin{array}{l}\text { Inadequately } \\
\text { measured }\end{array}$ & Not measured \\
\hline Biology & 30 & 5 & 17 & 8 \\
BLOC & 21 & 5 & 10 & 6 \\
BNTCH & 12 & 1 & 7 & 4 \\
BNTS & 20 & 12 & 3 & 5 \\
English I & 14 & 9 & 2 & 3 \\
English II & 13 & 8 & 2 & 3 \\
English III & 11 & 3 & 2 & 6 \\
English IV & 10 & 3 & 4 & 3 \\
History & 7 & 1 & 5 & 1 \\
Geography & 15 & 4 & 6 & 5 \\
Physics & 34 & 6 & 14 & 14 \\
\hline Total & 167 & $45(27 \%)$ & $69(41 \%)$ & $53(32 \%)$ \\
\hline
\end{tabular}

Based on a sample of 25\% of PACEs (3 out of 12) in each subject.

BLOC: Basic Life of Christ. BNTCH: Basic New Testament Church History. BNTS:

Basic New Testament Survey.

Table 6. Recall test items in PACEs by subject, ICCE General certificate

\begin{tabular}{|llll|}
\hline Subject & PACEs examined & Population & $\begin{array}{l}\text { \% Recall test } \\
\text { items }\end{array}$ \\
\hline English & 24 & 24 & 49 \\
Geography & 6 & 12 & 100 \\
World History & 12 & 12 & 100 \\
British History & 12 & 12 & 100 \\
Earth Science & 12 & 12 & 100 \\
Biology & 12 & 12 & 100 \\
Literature & 6 & 12 & 100 \\
BNTS & 12 & 12 & 100 \\
\hline
\end{tabular}

BNTS: Basic New Testament Survey 
Table 7. Recall test items in PACEs by subject, ICCE Advanced certificate

\begin{tabular}{|llll|}
\hline Subject & PACEs examined & Population & $\begin{array}{l}\text { \% Recall Test } \\
\text { Items }\end{array}$ \\
\hline English & 24 & 24 & 82 \\
Physics & 3 & 12 & 83 \\
BLOC & 3 & 12 & 100 \\
BNTCH & 12 & 12 & 100 \\
HOC II & 1 & 12 & 100 \\
Economics & 1 & 12 & 100 \\
Chemistry & 1 & 12 & 78 \\
\hline
\end{tabular}

HOC: History of Civilization.

Table 8. Grade boundaries for the ICCE

\begin{tabular}{|c|c|}
\hline Mean test score & Grade \\
\hline $98-100$ & $\mathrm{~A}^{*}$ \\
$96-97.99$ & $\mathrm{~A}$ \\
$92-95.99$ & $\mathrm{~B}$ \\
$88-91.99$ & $\mathrm{C}$ \\
$84-87.99$ & $\mathrm{D}$ \\
$80-83.99$ & $\mathrm{E}$ \\
\hline
\end{tabular}

(CEE, 2012, p. 54). NARIC (2012b) lists the same grade boundaries but does not include the $A^{*}$ grade. 